\title{
Understanding the massive open online course (MOOC) student experience: An examination of attitudes, motivations, and barriers
}

\author{
Heather B. Shapiro ${ }^{a}$, Clara H. Lee ${ }^{a}$, Noelle E. Wyman Roth ${ }^{\text {b, } 1}$, Kun Li ${ }^{\text {a }}$, \\ Mine Çetinkaya-Rundel ${ }^{\mathrm{a}}$, Dorian A. Canelas ${ }^{\mathrm{a}}{ }^{*}$ \\ a Duke University, Durham, NC 27708, United States \\ b Stanford University, Stanford, CA 94305, United States
}

\section{A R T I C L E I N F O}

\section{Article history:}

Received 22 April 2016

Received in revised form 28 January 2017

Accepted 2 March 2017

Available online 6 March 2017

\section{Keywords:}

Adult learning

Lifelong learning

Teaching/learning strategies

Post-secondary education

Media and education

Online learning

Qualitative analysis

Sentiment analysis

NVivo

\begin{abstract}
A B S T R A C T
During the widespread development of open access online course materials in the last two decades, advances have been made in understanding the impact of instructional design on quantitative outcomes. Much less is known about the experiences of learners that affect their engagement with the course content. Through a case study employing text analysis of interview transcripts, we revealed the authentic voices of participants and gained a deeper understanding of motivations for and barriers to course engagements experienced by students participating in Massive Open Online Courses (MOOCs). We sought to understand why learners take the courses, specifically Introduction to Chemistry or Data Analysis and Statistical Inference, and to identify factors both inside and outside of the course setting that impacted engagement and learning. Thirty-six participants in the courses were interviewed, and these students varied in age, experience with the subject matter, and worldwide geographical location. Most of the interviewee statements were neutral in attitude; sentiment analysis of the interview transcripts revealed that 80 percent of the statements that were either extremely positive or negative were found to be positive rather than negative, and this is important because an overall positive climate is known to correlate with higher academic achievement in traditional education settings. When demographic data was added to the sentiment analysis, students who have already earned bachelor's degrees were found to be more positive about the courses than students with either more or less formal education, and this was a highly statistically significant result. In general, students from America were more critical than students from Africa and Asia, and the sentiments of female participants' comments were generally less positive than those of male participants. An examination of student statements related to motivations revealed that knowledge, work, convenience, and personal interest were the most frequently coded nodes (more generally referred to as "codes"). On the other hand, lack of time was the most prevalently coded barrier for students. Other barriers and challenges cited by the interviewed learners included previous bad classroom experiences with the subject matter, inadequate background, and lack of resources such as money, infrastructure, and internet access. These results are enriched by illustrative quotes from interview transcripts and
\end{abstract}

\footnotetext{
* Corresponding author.

E-mail addresses: heatherbshapiro@gmail.com (H.B. Shapiro), claralee92@gmail.com (C.H. Lee), noellewymanroth@gmail.com (N.E. Wyman Roth), kkunlli@gmail.com (K. Li), mine@stat.duke.edu (M. Çetinkaya-Rundel), dorian.canelas@duke.edu (D.A. Canelas).

${ }^{1}$ Current address: QSR International, 55 Cambridge Street, Burlington, MA 01803, United States.
} 
compared and contrasted with previous findings reported in the literature, and thus this study enhances the field by providing the voices of the learners.

๑) 2017 Elsevier Ltd. All rights reserved.

\section{Introduction}

Massive Open Online Courses (MOOCs) are large-scale, open-access classes taught by university faculty via the internet using a variety of techniques such as weekly lecture videos/webcasts, online assessments, discussion forums, and even live video chat discussions and help sessions. Since the coinage of the term MOOC in 2008, this new avenue for education has raised a great deal of excitement and controversy in academia; these discussions have been recently chronicled and reviewed (Ebben \& Murphy, 2014; Rhoads, Camacho, Toven-Lindsey, \& Lozano, 2015). Some assert that these online courses carry the potential to revolutionize the boundaries of modern learning by making high-quality education available to a much more vast pool of students (Waldrop, 2013). To this end, early instructors using this format enthusiastically proclaimed “...there's no reason to limit the geographical boundaries. Anywhere there is an Internet connection, students can log-on to learn and get help" (Moore \& Janowicz, 2009, p. 4). MOOCs can also serve as an outlet for worldwide university outreach, expanding avenues for providing free, credible information to the general public. For example, some suggest that MOOCs will improve science and health literacy awareness and discussion among the public (Goldberg et al., 2015; Leontyev \& Baranov, 2013). The power of a MOOC can be realized "especially on taboo subjects such as acquired immunodeficiency syndrome (AIDS), tuberculosis, and contraception" (Liyanagunawardena \& Williams, 2014, p. 11). In cases where rapidly emerging fields are led by a small group of specialized experts, such as pharmacogenomics, MOOCs offer a route to efficiently improve in depth education for a larger group of students than can be handled by individual faculty at all institutions (Ma, Lee, \& Kuo, 2013). In professions where continuing education is desirable or required, MOOCs also provide an efficient venue for adult working professionals to gain new skills or stay current with new developments in their field. To this end, several MOOCs has been certified for the purpose of providing continuing education to adults in professional fields such as K-12 teaching (Vivian, Falkner, \& Falkner, 2014), and physicians are beginning to promote MOOCs for continuing medical education, particularly for medical practitioners in remote locations (Murphy \& Monk, 2013). Clearly MOOCs have tremendous potential for the promotion of life-long learning beyond the traditional classroom.

On the other hand, not all academics welcome MOOCs with open arms and view the possible future scenarios through such rose-colored glasses. Some educators fear that a rapid proliferation of MOOCs could compromise the quality of learning and lead to a deterioration of the post-secondary education system. These critics point to the importance of face-to-face classroom engagement, laboratory, clinical, or fieldwork, and other aspects of the college experience outside of the purview of formal coursework that would be difficult or impossible to replicate online (Cooper \& Sahami, 2013; Harder, 2013; Martin, 2012; McNutt, 2013). While most will now admit that online resources and online learning have a rapidly expanding place in higher education, the current common platform configurations (Fidalgo-Blanco, Sein-Echaluce Lacleta, \& GarcíaPeñalvo, 2015) and other limitations to synchronous, hands-on, and face-to-face experiences mean that MOOCs cannot so easily replace higher education as we know it today. Others point to the relatively advanced education levels (Emanuel, 2013) or high socioeconomic status (Hansen \& Reich, 2015) of a large percentage of early participants to dampen the claim that MOOCs are the solution to widening access to education. Moreover, since the overwhelming majority of MOOCs constructed to date are in English, language access can be added to the technology access barrier for many populations (Liyanagunawardena \& Williams, 2014), although the landscape in this regard is rapidly evolving. Another set of concerns cited revolves around the potential impact of MOOCs on academic life. Opponents of the MOOC movement point out that they contribute to the casualization of academic labor and threaten current institutions of higher education (Kolowich, 2013; Rhoads et al., 2015). Certainly the impact of MOOCs on the economic models of higher education constitutes a subject of intense interest (Hollands \& Tirthali, 2014; Hoxby, 2014), and some find the uncertainty in that arena unsettling. These and other ethical implications of MOOCs, including cheating/plagiarism or research ethics involved for the large datasets produced by human subjects, have been recently explored (Marshall, 2014).

\subsection{Prior research}

Distance, online, and other forms of e-learning have a rich history of research, reviews of that research, and development of models and frameworks (Arbaugh et al., 2009; Bernard et al., 2004; Childs, Blenkinsopp, Hall, \& Walton, 2005; Gikandi, Morrow, \& Davis, 2011; Leacock \& Nesbit, 2007; Lee \& Choi, 2011; Roca, Chiu, \& Martínez, 2006; U.S. Department of Education, 2010; Zawacki-Richter, Bäcker, \& Vogt, 2009). However, MOOCs and research specifically related to MOOC pedagogies and learner outcomes are relatively recent developments in this arena. The MOOC research literature prior to 2012 has been reviewed elsewhere (Liyanagunawardena, Adams, \& Williams, 2013).

Researchers from multiple disciplines have studied students' demographics, their performances, MOOC retention rates, best practices for course design and pedagogy, etc. Most studies about MOOCs to date have employed primarily quantitative or mixed-methods, such as analysis of course statistics and student survey data. For example, some of the early published 
research examined student learning in edX's first MOOC by evaluating course component access and completion, time spent on each resource online, scores on assignments, persistence, and some student demographic and survey data such as location, age, and selected reasons for enrolling (Breslow et al., 2013; DeBoer, Stump, Seaton, \& Breslow, 2013). More recent studies have used survey data to explore education research topics such as students' self-regulated learning behaviors in the context of MOOCs (Hood, Littlejohn, \& Milligan, 2015). Research into innovative course designs is beginning to show promise in increasing course completion rates (Fidalgo-Blanco et al., 2015; Fidalgo-Blanco, Sein-Echaluce, \& García-Peñalvo, 2016).

Researchers examining the effects of MOOCs on participants who cannot afford formal post-secondary education found that these learners were much less likely to have a college degree and were much more likely than a comparison group to enroll in a MOOC due to reasons of geographic isolation (Dillahunt, Wang, \& Teasley, 2014). Students who self-reported that they could not afford a formal college education were more likely than the comparison group to be using a MOOC to see if they wanted to enroll in a more formal college course and were also more likely to be awarded a certificate of achievement (Dillahunt et al., 2014).

Researchers examining the pedagogies employed in a cross-section of MOOCs determined that an objectivist-individual approach (Arbaugh \& Benbunan-Fich, 2006) was the most common framework and was used in all 24 MOOCs examined (Toven-Lindsey, Rhoads, \& Lozano, 2015). They conclude that MOOC creators should “ ...strive for more creative and empowering forms of open online learning" (Toven-Lindsey et al., 2015, p. 1).

Qualitative work in MOOC research is just beginning. The affective domain has been investigated through qualitative methods examining student writing in assignments and on discussion forums in MOOCs (Comer, Clark, \& Canelas, 2014). Motivation to learn in MOOCs has recently been studied from various perspectives, such as by examining aspects of language and social engagement (Barak, Watted, \& Haick, 2016). Finally, novel research methods such as blog mining have been developed to gauge the tenor of recent online discussions of MOOCs in various nontraditional publication outlets (Chen, 2014).

Motivation plays a key role in persistence and the extent of learning in all education environments, and there is a rich body of literature on the complex relationships between students' motivations, attitudes, and levels of engagement in a variety of learning contexts. Motivation theory is often invoked to explain why individuals choose to participate in certain tasks and their related effort level (Bandura, 1989a, b; Graham \& Weiner, 1996; Keller, 1979). Participation in MOOCs currently falls heavily into the category of "voluntary learning," so therefore it follows that motivation is especially important in determining individual differences in both total time spent on learning and effort intensity (Lei, 2010). While reviewing the rich history of the development of motivation theory in various contexts is beyond the scope of this contribution, interested readers are referred to reviews of motivation studies in online learning, in general (Bekele, 2010; Hart, 2012), and a recent detailed discussion of motivation research and its application to MOOCs, in particular (Barak et al., 2016; Ferguson \& Clow, 2015; Kizilcec \& Schneider, 2015).

\subsection{The present study}

Herein, we probe the future of online education through mixed-methods research. This involved analyzing surveys and interview transcript data from semi-structured interviews of participants in two Coursera courses, Introduction to Chemistry and Data Analysis and Statistical Inference, to gain a deeper understanding of the MOOC student experience. Our initial research questions were very broad:

1. Who are the students taking MOOCs?

2. What motivates students to take MOOCs?

3. What can we learn from students that may help improve the MOOC experience?

We aimed to use semi-structured interviews and qualitative coding techniques to probe more deeply into the relationship between motivation and engagement and explore emerging themes that to date have been only examined in a cursory way through surveys. For example, what challenges do participants face in the effort to have full engagement with and deep learning of the course materials? By understanding the motivations for students to take MOOCs, as well as the challenges one might face throughout such courses, we aim to provide insight into a poorly studied topic, providing a foundation for further research. Ultimately, such research could lead to platforms and pedagogies that maximize the number of positive student experiences and provide a better learning environment for those who choose to enroll.

This project examines students' motivations and perceived barriers and challenges by interviewing students in the two courses. The project can contribute to the literature on MOOC students' motivation and provide deeper understandings of how MOOC designers can help learners overcome their perceived barriers in taking the course.

\subsubsection{Description of courses}

The Introduction to Chemistry course is taught by the sixth listed author of one of the submitting institutions. The sessionbased course seeks to reach students with little to no background in the subject in order to prepare the students for further study in chemistry, which is needed for many science, health, and policy professions. Students are introduced to chemical problem solving involving topics such as atoms, molecules, ions, the periodic table, stoichiometry, chemical reactions, bonding, thermochemistry, and gas laws. The course features videos, discussion forums, problem sets, quizzes, and exams as 
well as an optional writing project assessed by peers. It was adapted from a campus-based course described in detail elsewhere (Canelas, 2015; Hall, Curtin-Soydan, \& Canelas, 2014). Since the completion of the data acquisition for this study, the course has been split into two shorter courses: Introduction to Chemistry: Reactions and Ratios and Introduction to Chemistry: Structures and Solutions.

The fifth listed author of one of the submitting institutions teaches the Data Analysis and Statistical Inference course. The session-based course aims to introduce students with little to no experience to the discipline of statistics while learning how to collect data, how to analyze data, and how to use data to make inferences and conclusions about real world phenomena. The course features videos, quizzes, and exams as well as data analysis labs in the R statistical language and an independent data analysis project assessed by peers. Since the completion of the data collection for this study, this course has also been split into a series of courses that make up the "Statistics with R" Coursera specialization.

\section{Theoretical framework}

This work is comprised of mixed-methods research guided by the literature and scholarship in motivation theory, elearning, and distance education theory (Bernard et al., 2004; Sun, Tsai, Finger, Chen, \& Yeh, 2008). We draw inspiration from the e-learning theoretical framework outlined by Aparicio and coworkers, who use an overlapping domains conceptual framework consisting of people (stakeholders), e-learning technologies including those designed for content and communication, and e-learning activities including pedagogical models and instructional strategies (Aparicio, Bacao, \& Oliveira, 2016). This is a comparative case study using the framework method for thematic development and analysis of semistructured interview data.

The theoretical framework for the study described herein involves overlapping domains of student motivations, barriers/ challenges, and demographics. Motivations for students to engage in a course can vary greatly from extrinsic to intrinsic in online learning environments (Hartnett, St. George, \& Dron, 2011). According to the pre-course surveys that the university sent out to their MOOC students, the majority of students signed up for a particular MOOC because they considered it fun or they were interested in the topic (Belanger \& Thornton, 2013). Other reported motivations for taking a MOOC included (1) supporting lifelong learning or gaining an understanding of the subject matter with no particular expectations for completion or achievement, (2) convenience, often in conjunction with barriers to traditional education options, and (3) to experience or explore online education (Belanger \& Thornton, 2013). Another study using survey data reveals that over half of students in an edX course chose to enroll in that course because they wanted to learn the knowledge and skills offered by that course (DeBoer et al., 2013). MOOC students' varied motivations also affect their participation in course activities. Yang (2014) found a positive correlation between MOOC students' intrinsic motivation and their participation in online discussions, but this relationship only occurred during later phase in the MOOC. Similarly, Halasek et al. (2014) stated "participants' interests and personal motivation determined whether and how they engaged with course materials..." (p. 162).

While online education provides learners greater opportunities to access learning resources, it also generates new challenges to online learners (Anderson, 2008; Song \& Hill, 2007). Lack of prompt responses from instructors, too many channels to obtain information online, lack of effective self-regulated learning skills, procrastination, and superficial participation in online discussion are some of the common challenges for online learners (Song \& Hill, 2007). MOOCs usually have thousands or tens of thousands of learners, so those challenges listed above can be even more obvious for MOOC learners. For example, because of the instructor to student ratio, many MOOCs use the discussion forum for students to ask questions instead of direct emails to or conversations with the instructor. Instead, peers are answering questions more often than the instructor. Additionally, many MOOC learners drop courses because of low self-regulated learning skills and procrastination (Diver \& Martinez, 2015).

Using our theoretical framework, we will probe motivations, barriers, and demographics as well as the overlap of these domains to draw conclusions about the experience of participants in the MOOCs.

\section{Data and methods}

\subsection{Data collection and description of sample}

Participants were recruited from both courses through announcements on the Coursera course sites, email messages, and posts on the courses' Facebook pages (Appendix A). The first stage of the interview subject recruitment was a survey in which students were asked about their spoken English fluency and whether or not they were willing to participate in an interview (Appendix B, document 1). At the time the survey was sent out, the Statistics course had roughly 10,000 students participating on a consistent basis in the course and the response rate was roughly $15 \%$. The response for the Chemistry course was slightly higher, with a $28 \%$ response rate from the roughly 3000 active students at the time the survey was sent out.

We used stratified sampling to identify a diverse set of interviewees based upon gender, age, educational background, income, and geographic location. We interviewed 20 students from Chemistry and 16 from Statistics; Table 1 shows a breakdown of the participants' demographics for each class. The interviewer guided the participant through a series of questions according to the interview guide (Appendix B, Document 2) over an audio-only internet line (via Skype) with interviews lasting from 30 to $45 \mathrm{~min}$. Using the semi-structured interview format, questions from the guide were supplemented by additional follow up questions as they arose. For instance, interviewees were asked about their educational background prior to the course, how they planned to use the course material after completion of the course, and how 
important the course was to them. The interviews were recorded, transcribed via a professional transcription service (CastingWords), and then analyzed with the aid of statistical and qualitative analysis software: RStudio and NVivo, respectively. To protect participant privacy, all data was de-identified to remove personal descriptors (names, emails) prior to analysis.

All subject recruitment and consent processes (Appendix C) followed protocol C0103, "Understanding the MOOC Student Experience through Qualitative Research Interviews," which was approved prior to beginning subject recruitment and data collection by one of the submitting universities' Institutional Review Boards (IRB).

We did not analyze the data for completion rates of the interview participants. As noted by DeBoer and colleagues, the extremely low barrier for "enrollment" in a MOOC means that traditional academic terms such as enrollment and participation need to be reconceptualized in order for them to regain meaning in this context (DeBoer, Ho, Stump, \& Breslow, 2014). This has caused researchers to begin analyzing retention data in alternative ways, such as by considering students who registered for verified certificates as a separate track (Engle, Mankoff, \& Carbrey, 2015) or by using latent profile analysis (a form of cluster analysis with a time dimension) (Wiebe, Thompson, \& Behrend, 2015).

\subsection{Sentiment analysis methods}

In order to understand the overall attitude of the interviewee responses, we analyzed the transcript text files using an automated sentiment analysis method. The analysis cross-referenced the words in each of the transcripts with an opinion lexicon of both positive and negative words (Hu \& Liu, 2004). The sentiment analysis followed the approach suggested by Breen (2014). Using this method, we calculated the sentiment score for each sentence in the transcript of interviewee comments using the following formula:

Score $=$ Number of positive words - Number of negative words

- If Score $>0$, the sentence is considered to have an overall 'positive' opinion

- If Score $<0$, the sentence is considered to have an overall 'negative' opinion

- If Score $=0$, the sentence is considered to have an overall 'neutral' opinion

A breakdown and quantitative analysis of sentiment scores by individual properties was performed to understand the overall attitude of different groupings of people who were interviewed.

\subsection{Qualitative analysis methods}

We also analyzed all interview transcripts through a manual text coding process using a framework method with emerging thematic analysis via NVivo, a qualitative data analysis software program. Prior to coding, interviewee names were

Table 1

Description of Sample: Interview participants.

\begin{tabular}{|c|c|c|c|c|}
\hline & & $\begin{array}{l}\text { Chemistry } \\
\mathrm{n}(\%)\end{array}$ & $\begin{array}{l}\text { Statistics } \\
\mathrm{n}(\%)^{\mathrm{a}}\end{array}$ & $\begin{array}{l}\text { Total } \\
\mathrm{n}(\%)^{\mathrm{a}}\end{array}$ \\
\hline \multirow[t]{2}{*}{ Gender } & Female & $9(45 \%)$ & $4(25 \%)$ & $13(36 \%)$ \\
\hline & Male & $11(55 \%)$ & $12(75 \%)$ & $23(64 \%)$ \\
\hline \multirow{5}{*}{ Highest Level of Education } & Less than HS & $1(5 \%)$ & $0(0 \%)$ & $1(3 \%)$ \\
\hline & Some College & $3(15 \%)$ & $0(0 \%)$ & $3(8 \%)$ \\
\hline & Associate's Degree & $1(5 \%)$ & $0(0 \%)$ & $1(3 \%)$ \\
\hline & Bachelor's Degree & $8(40 \%)$ & $11(69 \%)$ & $19(53 \%)$ \\
\hline & Graduate Degree & $7(35 \%)$ & $5(31 \%)$ & $12(33 \%)$ \\
\hline \multirow[t]{5}{*}{ Age } & $18-24$ & $6(30 \%)$ & $2(13 \%)$ & $8(22 \%)$ \\
\hline & $25-34$ & $6(30 \%)$ & $10(63 \%)$ & $16(44 \%)$ \\
\hline & $35-44$ & $3(15 \%)$ & $2(13 \%)$ & $5(14 \%)$ \\
\hline & $45-54$ & $2(10 \%)$ & $1(6 \%)$ & $3(8 \%)$ \\
\hline & $55+$ & $3(15 \%)$ & $1(6 \%)$ & $4(11 \%)$ \\
\hline \multirow[t]{6}{*}{ Annual Income } & $<\$ 20,000$ & $6(30 \%)$ & $5(31 \%)$ & $11(31 \%)$ \\
\hline & $20,000-34,999$ & $4(20 \%)$ & $2(13 \%)$ & $6(17 \%)$ \\
\hline & $35,000-49,999$ & $3(15 \%)$ & $0(0 \%)$ & $3(8 \%)$ \\
\hline & $50,000-74,999$ & $1(5 \%)$ & $6(38 \%)$ & $7(19 \%)$ \\
\hline & $75,000-99,999$ & $2(10 \%)$ & $1(6 \%)$ & $3(8 \%)$ \\
\hline & $100,000+$ & $4(20 \%)$ & $2(13 \%)$ & $6(17 \%)$ \\
\hline \multirow[t]{4}{*}{ Continent } & Africa & $1(5 \%)$ & $2(13 \%)$ & $3(8 \%)$ \\
\hline & Americas & $13(65 \%)$ & $3(19 \%)$ & $16(44 \%)$ \\
\hline & Asia & $3(15 \%)$ & $6(38 \%)$ & $9(25 \%)$ \\
\hline & Europe & $3(15 \%)$ & $5(31 \%)$ & $8(22 \%)$ \\
\hline
\end{tabular}

${ }^{a}$ Percentages provided do not always add up to $100 \%$ due to rounding. 
replaced with unique identifiers following the procedure outlined in the approved IRB protocol to protect individual privacy. In cases where illustrative quotes are given herein, interviewees are identified by this unique identifier, which includes both a number and a letter; the letter " $\mathrm{c}$ " indicates that the student was enrolled in the chemistry class, while " $\mathrm{s}$ " indicates that the student was enrolled in the statistics class.

Prior to the workshop described below, the core research team conducted some initial coding of small samples from the dataset and developed a coding protocol and initial structure of coding nodes (also called "codes" in some published literature) based upon the research questions and emerging themes. The coding structure was generated so that nodes were either organizational parent nodes or child nodes with literal meaning; these types of nodes, referred to as "substantive" nodes, are more readily interpreted than nodes used for more abstract, "theoretical" coding (Maxwell, 2005). The initial protocol that was developed through this process included thematic codes for challenges/barriers, community participation, course components, course feedback, motivation, and previous experience with the topic (see Appendix D for the portions of the final nodal structure relevant to the results described herein, and Appendix E for an illustration of how parent and child nodes are related).

Then, a team of nine researchers coded the interview transcript sources during an intensive, 1.5 day coding workshop. The third author, a social science researcher who specializes in qualitative methods and has been authorized by QSR International as a trainer for the software program (NVivo), designed and led the workshop. In addition to the workshop leader, the coding team was composed of members with a variety of skills and education levels: two were faculty members, one was a senior staff researcher with a $\mathrm{PhD}$, one was a staff member with a doctorate in education, and the remaining coders were undergraduates in their senior year of college. To establish agreement among coders and gain familiarity with the interview sources and coding process, on the afternoon immediately prior to the full day of coding, the entire coding team read and manually coded a selection of text from two interviews (one each from chemistry and statistics). The full coding team then discussed questions, emerging themes, and differences in individual coding. During the following morning, the coders transferred their coding into the NVivo software and individually coded a third selection. The group then again compared coding, discussed emerging themes and interpretations, agreed upon addition of new nodes, and refined and clarified definitions of existing nodes. Each coder was then assigned a set of interview transcripts to code individually. The workshop was structured to continually check coding; coders also collaboratively refined the coding protocol during the sessions as themes emerged. Throughout the workshop, individual coders kept memos or journals of their coding progress or questions in a place designated in the software for such memoing. After each period of individual coding, the coding team convened for a group discussion two more times during the workshop to compare coding, discuss questions, and resolve discrepancies. Coding was then cleaned by the workshop leader and analyzed further in NVivo.

\subsection{Limitations}

Before beginning the discussion of results, a few limitations of this work should be noted. Due to the small sample size, we can only make inferences about this sample of students and not towards the entire population of students taking MOOCs. In addition, there is slight selection bias due to the fact that only students with a self-reported professional working, native, or bilingual proficiency in English were interviewed. Both courses were taught in English, so students with a lower English proficiency might have had more difficulties in certain aspects of the MOOCs than others who were more fluent. Future studies might have multilingual interviewers who can successfully interview a wider range of students from different countries in order to understand a larger portion of the population.

In terms of limitations in the coding and analysis aspect of the work, only interviewee responses were coded, and understanding that text in context during the analysis stage becomes difficult when analyzing sentences separately from each other. To mitigate this effect during the coding workshop, interviewer statements and questions were visible, and each coder worked through an interview from start to finish to maximize understanding of context. Lastly, it is possible for the interview responses to have errors in their transcription, leading to incorrect assumptions about the student. To reduce the impact of this limitation, a professional transcription service was employed. Nonetheless, errors of omission, misinterpretation, incorrect identification of respondent, and assumptions that all statements had equal verbal emphasis are some of the most common errors when dealing with interview transcriptions (Krueger, 2006).

\section{Results and discussion}

\subsection{Sentiment analysis}

The sentiment analysis extracted 10,954 total interviewee statements: 6183 from participants in the chemistry course, and 3576 from participants in the statistics course. This analysis of the students' transcripts showed that about 80 percent of the comments were neutral (8993 neutral comments, see Fig. 1). That means that, in a particular statement, there were just as many positive phrases as there were negative. Overall, the average sentiment score was about 0.162 , which means that the comments had a slightly positive skew. The frequency of positive, negative, and neutral statements can be seen in Fig. 1. However, in order to understand what students liked and disliked about the course, we continued the analysis without neutral statements. We looked at only positive and negative statements to understand any extreme sentiments that students might have in the course or MOOCs in general. 


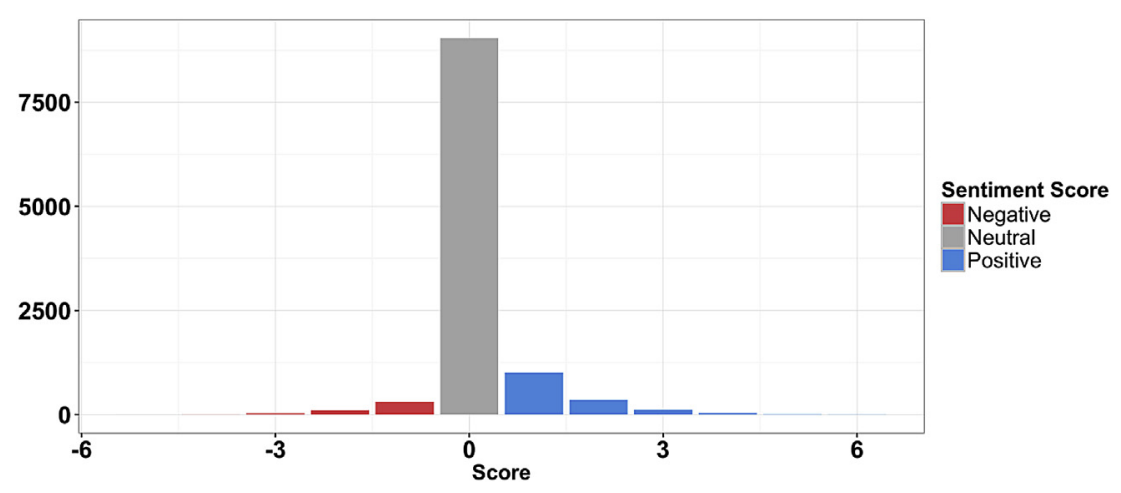

Fig. 1. Frequency of positive, negative, and neutral statements in the 10,954 total statements.

Of the 650 statements that had extreme sentiment scores (i.e. above +2 for positive and less than -2 for negative), $80 \%$ of the statements were positive (520 extremely positive statements: 292 from chemistry participants and 228 from statistics participants; 130 extremely negative statements: 80 from chemistry participants and 50 from statistics participants). This does not imply that everything that a student said in the interview was positive, but this indicates that students were generally pleased with different aspects of their course. This positive skew might be expected, as the students who were interviewed liked the course enough to participate in the study and remain in the course past the midway point.

The demographics of the interviewees were considered in order to better understand if certain groups might have more positive perceptions of the online platform. The groups with more positive statements and the groups with more negative statements were then analyzed question by question using NVivo. After breaking down the demographics, and repeating the sentiment score process for each individual, we see that there are some differences in the proportions of positive and negative statements by different demographic groups. Fig. 2 displays the proportions of negative and positive sentiments by demographic groups based on age, gender, education, income, and continent. We can see that bigger differences in percentage of positive sentiments occur across the levels of previously completed education, with the highest level of positive sentiments among those with a Bachelor's degree, and across the levels of gender, with statements by males being overall more positive than those by females.

A Chi-Square Test for Independence was also performed to evaluate whether these data provide convincing evidence of an association between these variables and whether or not the statement has a positive sentiment. Table 2 summarizes the results of this analysis. While age and income were not significantly associated with whether or not a statement was positive, education, gender, and continent were found to be significantly associated with whether a statement was positive or not positive.

To further this investigation, we aggregated the data at the interviewee level and built a linear regression model for predicting the percentage of positive statements by each interviewee based on these demographic attributes. We started with a full model including age, gender, education level, income, and continent as well as the number of statements made by that interviewee in order to control for the varying lengths of interviews. We then conducted backwards variable selection based on AIC which yielded a final model that included only education and gender. The regression coefficients of this final model, as well as their confidence intervals, are displayed in Fig. 3. We can see that having a Bachelor's or graduate degree is positively associated with higher levels of positivity towards the course, compared to having a high school degree or lower. Conversely, being female is negatively associated with positivity towards the course, compared to being male, however this difference is not highly statistically significant.

The sentiment analysis described so far gives a general understanding of how the students interviewed felt about the course in terms of overall attitude (positive, negative, or neutral). Understanding overall attitude is important because of the reported link between positive educational climates and increased student motivation for learning and academic achievement (Cohen, McCabe, Michelli, \& Pickeral, 2009). The attitude of the interviewee statements was more positive than negative, indicating that MOOCs offer a constructive learning environment with manageable levels of frustration; this supports the findings of previous work examining the attitude of student writing on MOOC forums (Comer et al., 2014). The qualitative analysis described in the next section provides a more detailed portrayal of how students responded to each individual question, providing the authentic voice of the students and allowing for more in-depth inferences on what facilitates a better atmosphere for students in MOOCs.

\subsection{Qualitative analysis}

The qualitative coding process provided a framework method which allowed us to code for emerging themes. Through this process and the subsequent analysis of coded data, we began to better understand students' motivations while delving into the challenges and barriers that affected participant success in reaching their goals for the courses. 


\section{Percentage of Negative and Positive Statements by}
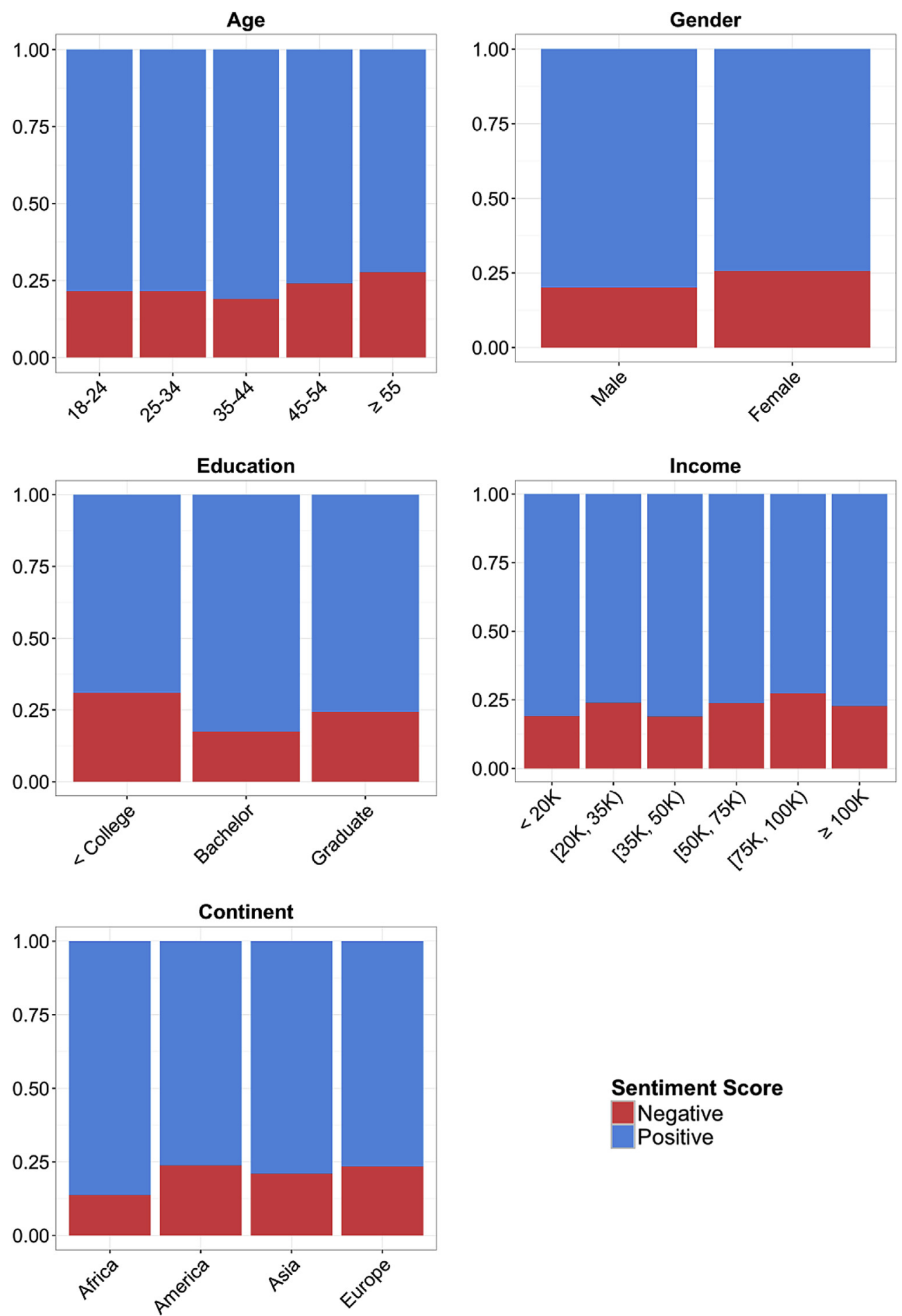

Fig. 2. Percentage of positive and negative statements by variable.

\subsubsection{Motivations}

For our purposes, we defined motivation as "a reason for taking or completing the course." We coded 356 mentions of various motivations found in 35 out of 36 interviews (Fig. 4). The most commonly coded node was knowledge; most students are intrinsically motivated to augment their knowledge in statistics or chemistry (referenced in 33 interviews). Other common 
Table 2

Results of Pearson's Chi Square Test of Independence of each variable vs. positive sentiment.

\begin{tabular}{llll}
\hline & $\mathrm{X}^{2}$ Statistic & $\mathrm{df}$ & $\mathrm{p}$-value \\
\hline Age & 6.72 & 4 & 0.1515 \\
Gender & 7.97 & 1 & 0.0048 \\
Education & 30.12 & 2 & $2.88 \mathrm{e}-07$ \\
Income & 8.27 & 5 & 0.1420 \\
Continent & 8.86 & 3 & 0.0312 \\
\hline
\end{tabular}

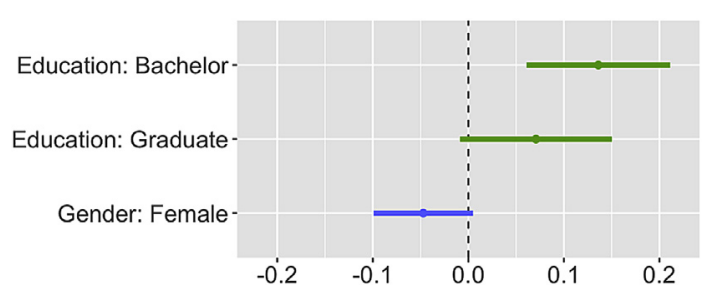

Fig. 3. Regression coefficients (and confidence intervals) for predicting positive sentiment percentage.

themes in motivation that were coded to nodes include work (referenced in 23 interviews), convenience (mentioned in 21 interviews), and personal interest (referenced in 20 interviews). The least commonly coded motivation nodes were pursuit of a hobby, motivation coming from the high quality of the course, or motivation arising from the MOOC materials being easier to understand than previously encountered materials. Some of the coded motivations are expanded in more detail below with illustrative quotes.

As shown in Fig. 4, by far the most commonly coded reason for taking or staying in both courses was students' desires to learn and improve their knowledge about the topic ( $92 \%$ of interviewees). For some, knowledge was the major or only stated motivation. For example, a statistics student noted "the main reason was I was interested in learning the material" (Interviewee S2), while a chemistry participant stated "I decided to take this course just because I wanted to learn chemistry, and that's it" (Interviewee C18). By contrast, interviewees were relatively ambivalent about the ability to earn a certificate as a

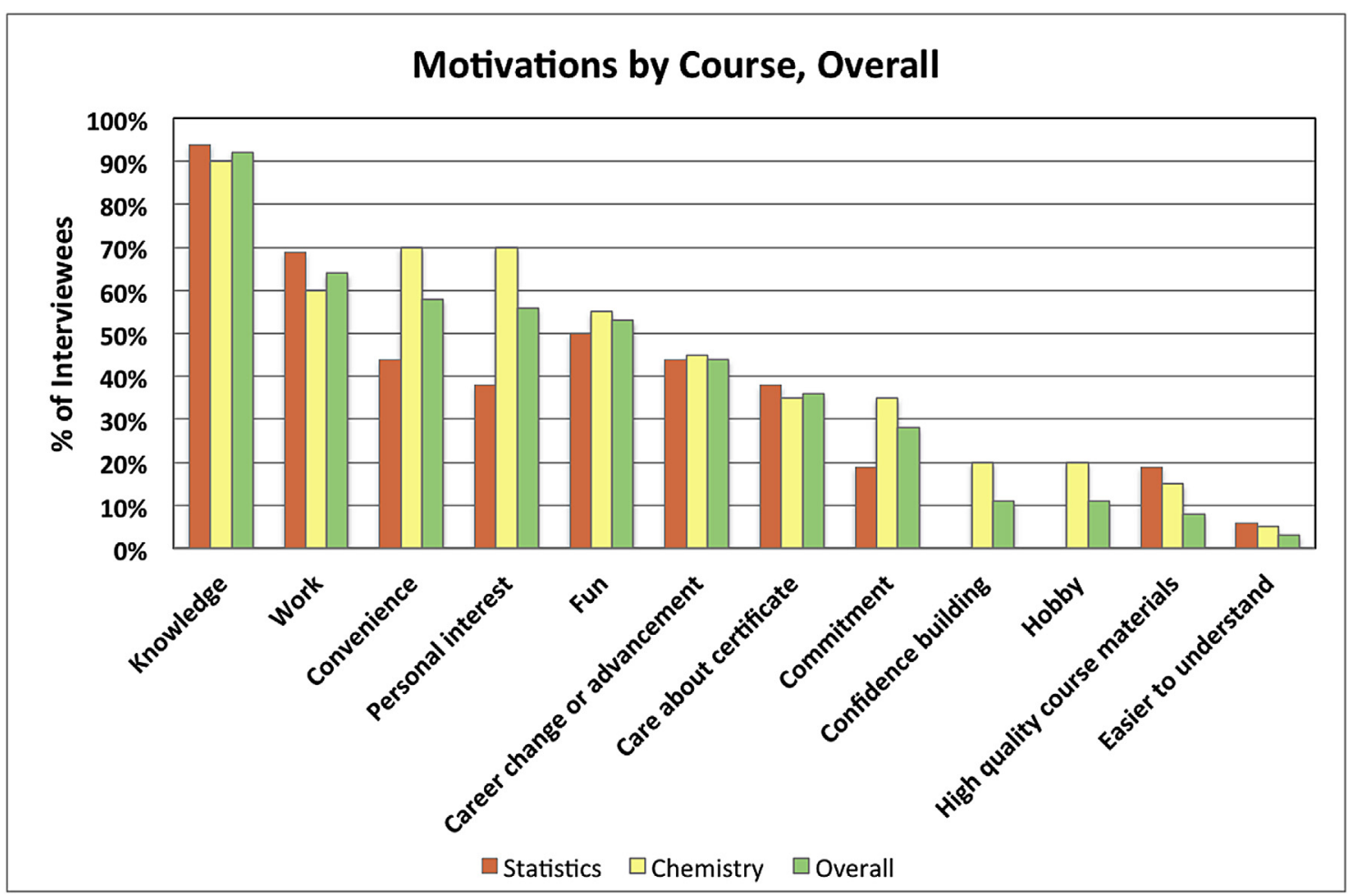

Fig. 4. Percent of Interviewees $(N=36)$ who made statements coded to motivation nodes (391 total statements coded to these nodes.) 
motivator, which is discussed in more detail below. While some education policy pundits might argue that our society is abandoning the goals of deep and meaningful learning and veering toward an age of credentialing, it's clear that the vast majority of our interviewees were more interested in learning content than earning any sort of credential. One statistics participant summed up this sentiment by simply stating, "it's not about getting the qualification. It's the process of learning" (Interviewee S13).

While gaining knowledge was clearly the most frequently coded motivator for participants, references to participants' current jobs were also very prevalent in the interview transcripts. Sixty-four percent of interviewees were coded as mentioning an extrinsic motivating factor related to their work. For example, one statistics student stated, "I'm not that familiar with processing data, so the course is helping me perform better in my job, and understanding the data and understanding technology to really filter through the data and make sense of it" (Interviewee S10). Of particular note is that five interviewees were teachers whose motivations for taking the course involved improving their ability to teach the same material. One participant noted "I am just looking at the different perspectives of explaining things, because I'm in teaching, so I need various ways to explain to my students" (Interviewee C3). Other teachers participating in the MOOCs gained insights by revisiting education from the student's perspective. For example, one interviewee described the impact of being in an economically diverse pool of participants and how that shed light on the learning experiences of his or her own students:

...teaching undergraduate students chemistry, some of them are coming from very poor background, very weak knowledge of chemistry. Learning this, putting myself in the position of a student and learning these through Coursera also improves the way I interact with my students, especially those that are coming from very poor background. (Interviewee C1)

Over one quarter (28\%) of the interviewees made statements coded as motivation to take the MOOC to begin, change, or advance their careers. Some nontraditional students viewed the MOOCs as an accessible avenue for gaining the necessary foundation for such a leap. As an illustration, one chemistry student described a growing desire to enter a healthcare profession:

... after having a chronic illness in my early 20's, I got married young and I never really got the opportunity to pursue higher education. Medicine became a no-brainer because there really isn't anyone in my immediate family or friend groups whose lives haven't been touched by illness and haven't been hurt by poor doctors ... It's an area that's always interested me that I'm looking at and going "Well, you know what, if I can bring a little humanity to this in my little corner of the world, it would be a good thing to do. (Interviewee C6)

Without a doubt, in the cases studied here, employment concerns were powerful motivating factors. As previously noted, the application of learning in MOOCs to current employment (coded as work) and future employment prospects (coded as career change or advancement) were new themes that emerged in our research. Example interviewee statements coded as work include "The demands of the IT business are such that you need to learn, all the time." (Interviewee S3) and "I wanted to use it as an aid in my classroom, as well as to refresh some of my memory from general chemistry, as I teach it" (Interviewee C9). Career advancement themes emerged for some interviewees and included statements such as this one about further schooling:

The reason I take the Coursera courses is because I have applied in graduate programs in the US. It's important for me to get used to the English lessons first. This data analysis is important to my future study, so that's why I chose this class. (Interviewee S9)

Both of the courses in our study relate to science, technology, engineering, and mathematics (STEM) professions, so the strength of the work motivation might not be as pervasive in MOOCs about subjects that might be more often equated to leisure pursuits.

Many of the interview statements that were coded to motivation nodes reinforced and augmented the findings of Hew and Cheung (Hew \& Cheung, 2014). These researchers scoured previously published academic literature and noted "four reasons why students sign up for MOOCs: the desire to learn about a new topic or to extend current knowledge; they were curious about MOOCs; for personal challenge; and the desire to collect as many completion certificates as possible" (Hew \& Cheung, 2014, p. 45). On the latter point, both of the courses offered the ability for participants to earn a certificate called a "statement of accomplishment" or a "statement of accomplishment with distinction" upon successful completion of set percentages of the assignments. Interviewers asked the students how important the course was to them, and $80 \%$ of the students interviewed made some mention of these course certificates in their response. Fig. 5 shows that, among the students who mentioned the certificate, about $36 \%$ cared about successfully obtaining the certificate, $25 \%$ were indifferent to whether or not they earned it, and about $31 \%$ of the students mentioned not caring about receiving the certificate at all. As an illustration, a statistics participant noted "I'd say the certificate matters a little. I would want to get it. But if it didn't include one, then I would take it anyway just for the material" (Interviewee S5). Some clarified that the certificate is important, but not as important as the knowledge: "Mostly, it's a matter of gaining knowledge, gaining experience competencies, but not the certificate, although it's also very motivating to be above 80 percent and get the certificate with a distinction" (Interviewee S3).

Indeed, our findings regarding the motivating power of the certificate offers a counterpoint to the work of Hew and Cheung (2014) and others (Greene, Oswald, \& Pomerantz, 2015; Phan, McNeil, \& Robin, 2016), while affirming the deduction that many learners are not seeking any sort of credential or course credit (Kolowich, 2013). Twenty percent of 


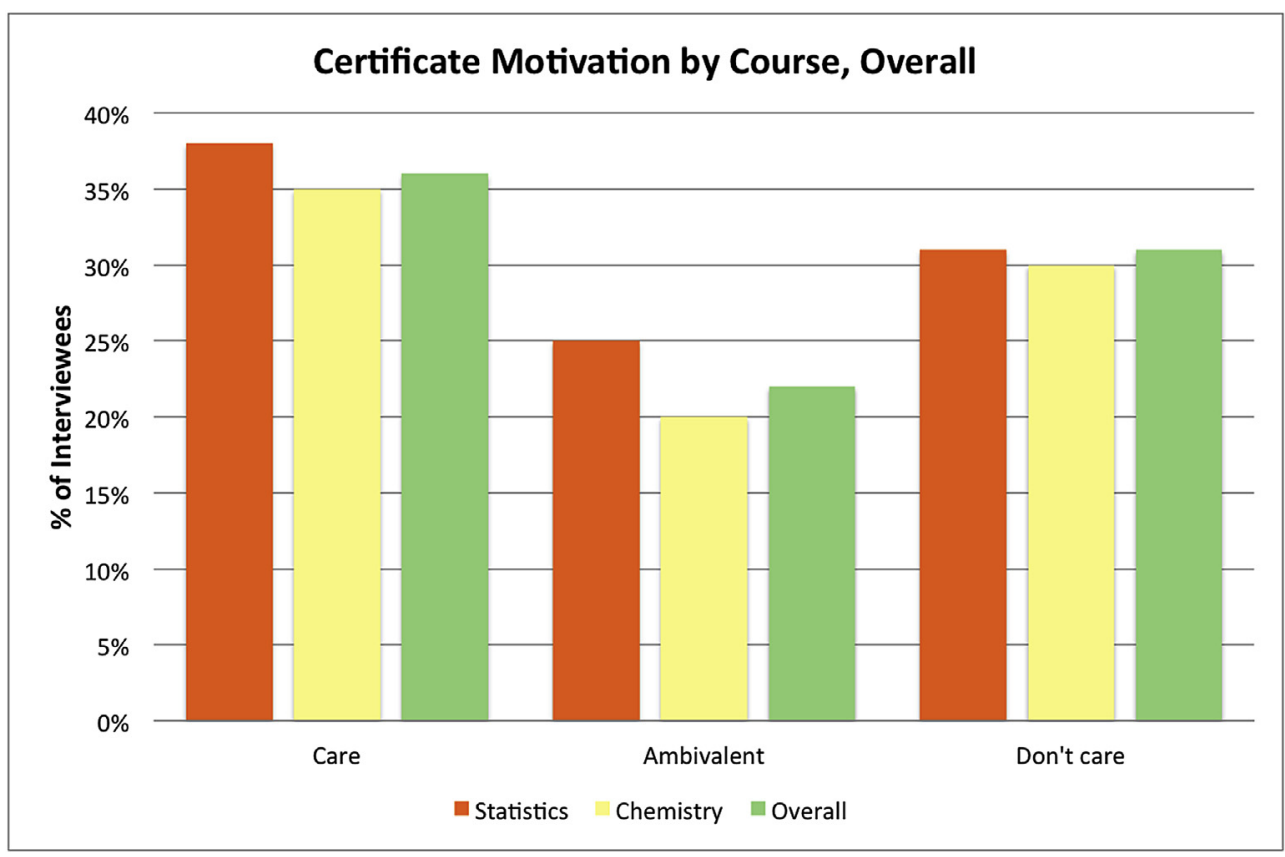

Fig. 5. Interviewee attitudes about earning a certificate, or "statement of accomplishment" (73 statements coded to certificate nodes.).

interviewees did not mention the certificate at all, and of those who did mention the certificate, we coded the majority of comments to either "ambivalent" or "don't care." So, while students with a high achievement orientation might find earning a certificate to be motivating, this feature of MOOCs did not motivate the majority of participants in these particular courses. This finding is particularly interesting because both MOOCs in our study had multiple choice quizzes that could be submitted multiple times. In prior work analyzing motivations in online courses, Hoskins and van Hooff noted that "of those that repeated an online quiz, improvement was more likely in those with lower achievement orientation" (Hoskins \& van Hooff, 2005, p. 177). Perhaps the landscape and format of MOOCs offers a comfortable learning venue for students with relatively low achievement orientation? More research in this area is needed.

Another theme that emerged during our data analysis is that students take MOOCs because they are convenient-MOOCs are free and can be taken any time of the day or night-and for some students this flexibility was motivating. As an illustration, the following excerpt was coded to convenience: "On Coursera, it's just about me and whatever I feel like learning and I can take all the time I want to on it. It's online, I don't have to travel 30 min out of my way" (Interviewee C10). This affirms the findings of earlier research via questionnaires that flexibility and ease of use are critical reasons that online course participants-particularly adult learners with jobs, family, or other obligations-find satisfaction in their engagement with elearning (Arbaugh \& Duray, 2002; Sun et al., 2008). As another example, a previous study comparing 17 course sections that included some asynchronous online "distance" sections, traditional face-to-face sections, and blended sections found "there were no significant differences in perceived learning by students associated with mode of delivery... while convenience was rated highest in the distance sections" (Benbunan-Fich \& Hiltz, 2003, p. 298).

MOOCs offer additional flexibility to learn online in the absence of needing to earn a certain grade, which might explain the prevalence of mentions of fun or personal interest as motivators ( 28 and 34 references, respectively). We hypothesize that these elements of motivation to enroll in the first place might be more difficult to find in a traditional campus-based or creditbased online STEM course where all students receive a letter grade at the end. Several students expressed this sentiment. Many students found it convenient to explore only the portions of the course that interested them without feeling guilt over not completing every single aspect of the course. For example, one student described experience with MOOCs "I've actually found them very enjoyable. I think what I do enjoy is the freedom, so I don't necessarily have to participate in all the quizzes and all the assignments if I don't want to" (Interviewee S10). Participants reveled in this sense of liberty; one noted "I think there's more freedom to it than there is in a university course. And that's one of the things I like about it" (Interviewee C18). For some, the fact that the course was free and ungraded led to flexibility in academic exploration:

...if there's a course like introduction to algorithms or chemistry and I don't know if I have time or the academic background to complete the course, I'd say, "Hey, just take the course. See how it goes. You can dip your toes in and if it works, it works. If it doesn't, it doesn't. It's no big deal." It allows me to try things out that I wouldn't otherwise try. (Interviewee C12)

While the increasing cost of college education prevents many individuals from exploring new academic subjects, MOOCs provide an opportunity to learn without barriers to entry. One participant with a job and family demands said the following 
about post-secondary education opportunities: “...it would mean enrolling in some alternative university. Typically, I wouldn't have time to do that. If I wanted to enroll at Duke, it would be completely unreachable because I'm six time zones away" (Interviewee S3). Another appreciated the chance to learn online because "I'm able to do it because I'm in this remote location and there are no resources" (Interviewee C19). The fact that MOOCs are convenient and free does not imply that participants in MOOCs take learning for granted; a chemistry student summarized his or her attitude about MOOCs succinctly: "I take them very seriously" (Interviewee C14).

Although our analysis of the interviews indicate that acquisition of knowledge was the primary motivator for most participants, measurement of meaningful or deep, long-term learning in a MOOC setting is difficult. Most research to date mentioning assessment of learning has focused on student self-reports of learning primarily through surveys and questionnaires (for example, Gooding, Klaas, Yager, \& Kanchanaraksa, 2013). More research is needed to determine whether a connection exists between participant motivations in MOOCs and deep, meaningful learning.

In summary, analysis of the interview transcripts captured the learners' authentic voices regarding motivations for enrolling in the MOOCs. By coding these transcripts, we discovered both a wide range of learner-expressed motivations and, in many cases, a deep and rich insight into the specific ways that extrinsic and intrinsic factors motivated the students. In some but not all settings, learner comments were aligned with extrinsic motivation, but other learners had no extrinsic motivations coded from their interviews. On the other hand, all learners made comments that were coded to various types of intrinsic motivations for participating in the MOOCs. Our interpretative explanation (Sandelowski \& Barroso, 2003) is that participants in MOOCs represent a diverse cross section of the world's populations, and this leads to some great disparities in extrinsic motivations by credentials such as the ability to earn a certificate, while common intrinsic motivations, such as the desire to gain knowledge, convenience, and personal interest, cut across both courses.

\subsubsection{Challenges and barriers}

Parkes et al. note that "learning in e-learning environments developed in accordance with social constructivist principles can be challenging" (Parkes, Stein, \& Reading, 2015). Not surprisingly, themes in challenges and barriers developed during the interview and coding process. These themes included circumstances that affected the student's ability to take and stay in the MOOC and challenges cited for that student's education in general.

We inductively coded 227 references to barriers and challenges in 35 (of 36) interviews (Fig. 6). By far the most commonly coded barrier in interview transcripts from students in both courses was lack of time, with 78\% of interviewees mentioning it. Other commonly coded barriers included bad experiences in the past within the subject or topic (33\% of interviewees), inadequate background in the topic (31\% of interviewees), and difficulties inherent to the online format (i.e., not being able to raise your hand and ask the teacher a question). When these barriers were broken down by education level, students with less than a bachelor's degree mentioned these barriers more often than any other education level.

Since the most frequently coded node in this theme was lack of time, it appears that many MOOC students we interviewed were not prepared for the time demands of taking a university-level online course. Although both courses provided estimates that greater than six hours per week would be needed for success in the course (published on their landing pages), many students attempted to stay in the course while devoting substantially fewer hours. An illustration, one student noted, "I want to really learn it. In my experience ... it's hard to learn something when you only spend a couple of hours a week, especially chemistry" (Interviewee C14). Another participant expressed the tradeoff between employment and time spent on the MOOC: "I don't think I've actually been spending enough [time], to be honest ... my workload's been such that I haven't completed any of the quizzes over the last two weeks" (Interviewee S10). Some learners noted that the quantity and rigor of material impacted their time management:

I would say my learning style is go slowly as I need to fully understand the concept, so I can basically recreate the concept, if needed and that I don't really need to memorize anything, because I can just logically put it back together if I need to. I couldn't do that in this course, because there was just too much stuff. I couldn't take the time to fully understand things, because I just needed to move on to the next thing. (Interviewee C12)

The prevalence of this theme confirms the findings of others (Park \& Choi, 2009) that many adult learners are juggling multiple demands and that this leads to a disconnect between the time expectation for adequate learning in a quantitative college-level course and the time that they have available outside of their other commitments. Park and Choi have noted that “external factors such as organizational supports, financial problems, and time constraints have been known to be crucial obstacles to adults' participation in learning" (Park \& Choi, 2009, p. 215). They found that "organizational support" and "relevance" were particularly important for preventing adult learner drop out from fee-based online coursework, suggesting that work-related time constraints played a role in that particular study (Park \& Choi, 2009).

The next most common barrier coded for participants in both courses was a previous bad experience with the subject matter, school, or online learning tools. Although some interviewees enjoyed the subjects enough in traditional classroom settings to have studied them throughout their schooling, other participants had suffered some setbacks or discouragement in their prior attempts in the subjects of math, statistics, science, or chemistry. One statistics learner recalled, "honestly, I had a lot of problems with the statistics because in my Bachelor's, I didn't like statistics or mathematics" (Interviewee S1). Several chemistry participants had also not enjoyed or excelled during their first contact with the subject in formal schooling, and some had even internalized that as a personal deficit, as illustrated by this quote: 


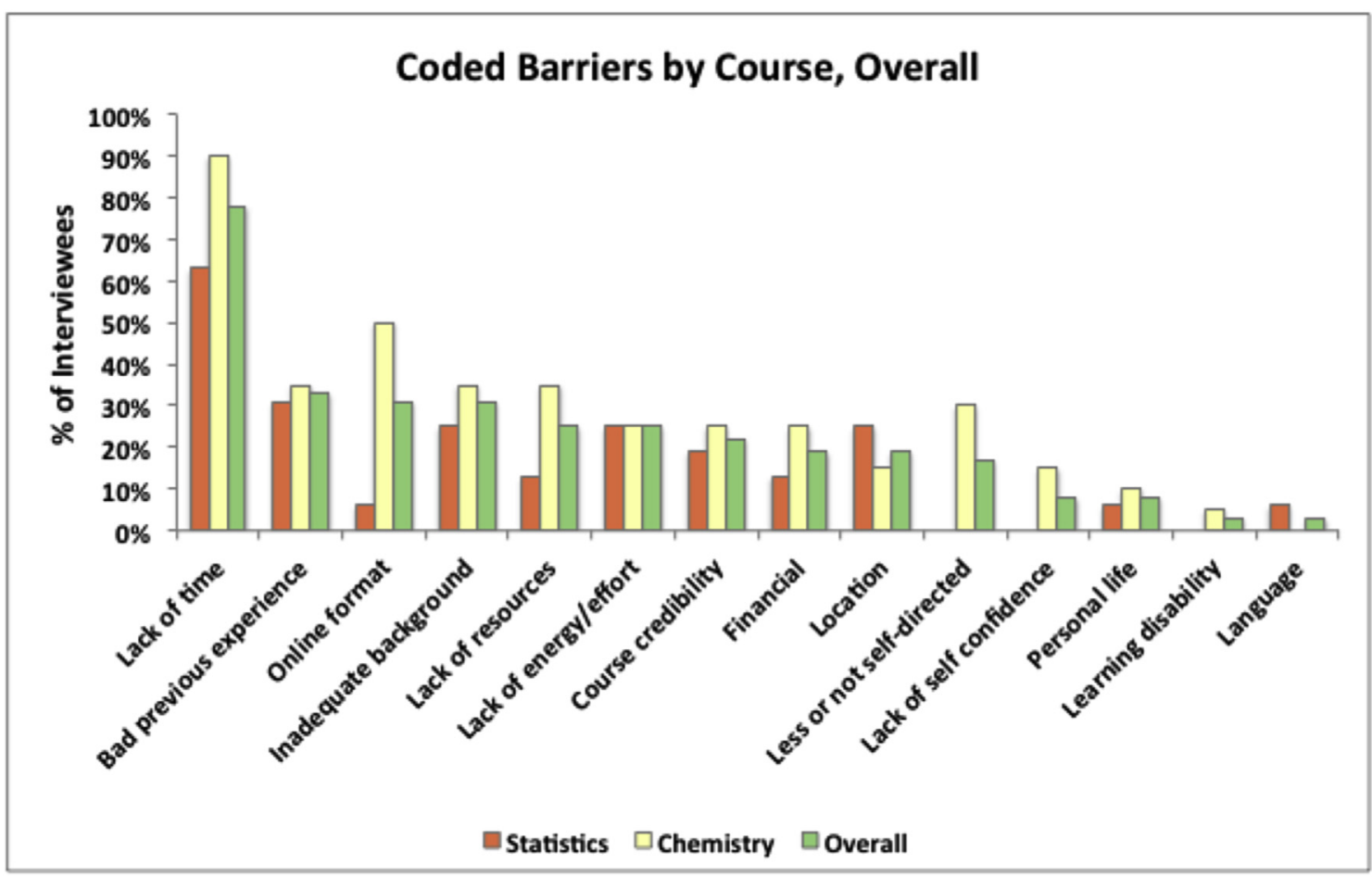

Fig. 6. Percentage of Interviews containing text coded to barriers by course; 261 total statements coded to this node.

I got like a one on the AP chemistry exam. It was something that I didn't take too seriously ... I think maybe I didn't have a great experience in the classroom, so I certainly went into college thinking, "OK, math and science isn't for me." (Interviewee C19)

Barriers or challenges were coded as overlapping less frequently than motivations. The barriers most frequently cited together were lack of energy, effort, or interest and lack of time (14\% of interviewees). One interviewee explained, "I haven't done it for the past couple of weeks. I did the first couple of weeks but I've been kind of busy with work and low energy the last couple of weeks so I haven't really been doing much with it" (Interviewee C20).

As previously mentioned, the student's geographic location and corresponding lack of resources often proved to negatively impact their experience in the MOOC. Eleven percent of interviewees mentioned that their geographic location and corresponding lack of resources created barriers for the course. We found that poor Internet connectivity was the most commonly coded problem:

It's very slow to fill it in China ... The professor has provided another way for the Chinese students but sometimes we can't, we just can't. The video I usually download it because it is very slow to watch it online, but if you download it you cannot see the quizzes in the video. (Interviewee S9)

However, in some cases, MOOCs help students overcome the lack of resources in their location. A chemistry student noted that "I think in pretty much every way, learning in a classroom is better, but learning online, I'm able to do it because I'm in this remote location and there are no resources" (Interviewee C19).

\section{Conclusions}

The authentic voice of the learner is extremely important in education research, and our study recognizes this value and delves into an analysis of learner statements about their experiences in MOOCs. Quantitative analysis of learner interview transcripts revealed that the attitude of the interviewee statements was more positive than negative. This result indicates that the MOOCs could offer a constructive learning environment with manageable levels of frustration. Learners who had already earned a bachelor's degree as their highest level of education were more positive than learners who had not completed a college degree or those who had an advanced degree, and this was a highly statistically significant result. We can conclude that participants with lower levels of formal education were more likely to feel lost or become frustrated by the technical and quantitative subject matter, while those who had advanced degrees were perhaps more likely to view the courses through the critical lens of an academic reviewer. Students from America made fewer positive statements than students from other countries, and have on average 15 percent fewer positive statements than students from Africa. This finding from the 
sentiment analysis suggests resilience and optimism on the part of students in less developed countries, who were more positive in their commentary in spite of the fact that they were also more likely to note challenges with infrastructure and internet access that affected consistent access to the course materials.

The qualitative data presented herein add depth and richness to the existing general knowledge about MOOC learners, lending insight into known factors such as the range of motivations. All learners voiced at least one of a number of common intrinsic motivations, such as the desire to gain knowledge, convenience, work, and/or personal interest. The abundance of statements coded to these four learner motivations cut across both courses, indicating that the results are not discipline specific. While this confirms the existing body of knowledge about MOOC learner motivation, further research would need to be conducted to evaluate whether these results apply to other open online learning settings. Lack of time was by far the most prevalently noted challenge or barrier, suggesting that time is the most precious resources to learners in all settings! Other learner-cited barriers and challenges included previous bad classroom experiences with the subject matter, inadequate background, and lack of resources such as money, infrastructure, and internet access. Clearly, the huge range of learner access to the critical resources for personal growth (such as primary education and income) and the breadth of existing municipal infrastructures worldwide must be considered by educators and course designers when creating open online courses for international audiences. Indeed, the qualitative details about the motivations and barriers experienced by the diverse international learner populations should continue to be explored and considered to gain more rich understandings of how all types of online students interact with their learning environments. To this end, the study presented herein has an important place in the dialog about the role of MOOCs in education because it presents the authentic voices of the learners.

\section{Acknowledgements}

We would like to acknowledge the work of the coding team: in addition to the study authors, Maria Elena Carvajal, Joel Herndon, and Anthony Weishampel are thanked for their coding work on the project and participation in the coding workshop. Charlotte Clark is thanked for providing feedback to the second author on the development of the semi-structured interview guide and for suggesting expert consultants for organizing the coding workshop. We thank Lynne O'Brien for her leadership in Duke's digital and online education initiatives. We are grateful that the Center for Instructional Technology (CIT) approved our course proposals and that CIT's wonderful personnel provided design ideas and technical support for the creation of the MOOCs. The research work described herein was generously financially supported by the Bass Connections theme in Education and Human Development, and we thank Thomas Nechyba for his leadership of that theme. The Duke University Institutional Review Board (IRB) is thanked for their constructive feedback and approval of IRB Protocol CO103, "Understanding the MOOC Student Experience through Qualitative Research Interviews."

\section{Appendix A. Supplementary data}

Supplementary data related to this article can be found at http://dx.doi.org/10.1016/j.compedu.2017.03.003.

\section{References}

Anderson, T. (2008). Towards a theory of online learning. In T. Anderson (Ed.), Theory and practice of online learning (2nd ed., pp. 45-74). Edmonton, AB: AU Press. $\quad$ Retrieved http://books.google.com/books?hl=en\%26lr=\%26id=RifNwzU3HR4C\%26oi=fnd\%26pg=PA45\% 26dq=online+learning+challenges\%26ots=Sf8jIjOZtx\%26sig=1xxfYFRo8mMAInMujvWOgt9sgZA.

Aparicio, M., Bacao, F., \& Oliveira, T. (2016). An e-learning theoretical framework. Educational Technology \& Society, 19(1), 292-307.

Arbaugh, J., \& Benbunan-Fich, R. (2006). An investigation of epistemological and social dimensions of teaching in online learning environments. Academy of Management Learning and Education, 5(4), 435-447.

Arbaugh, J. B., \& Duray, R. (2002). Technological and structural characteristics, student learning and satisfaction with web-based courses: An exploratory study of two on-line MBA programs. Management Learning, 33(3), 331-347.

Arbaugh, J. B., Godfrey, M. R., Johnson, M., Pollack, B. L., Niendorf, B., \& Wresch, W. (2009). Research in online and blended learning in the business disciplines: Key findings and possible future directions. Internet and Higher Education, 12(2), 71-87.

Bandura, A. (1989a). Social cognitive theory. In R. Vasta (Ed.), Six theories of child development: Vol. 6. Annals of child development (pp. 1-60). Greenwich, CT: JAI Press.

Bandura, A. (1989b). A social cognitive theory of action. In J. P. Forgas, \& M. J. Innes (Eds.), Recent advances in social psychology: An international perspective (pp. 127-138). North Holland: Elsevier.

Barak, M., Watted, A., \& Haick, H. (2016). Motivation to learn in massive open online courses: Examining aspects of language and social engagement. Computers and Education, 94, 49-60.

Bekele, T. A. (2010). Motivation and satisfaction in internet-supported learning environments: A review. Journal of Educational Technology \& Society, 13(2), $116-127$.

Belanger, V., \& Thornton, J. (2013). Bioelectricity: A quantitative approach. Consortium Conference. Retrieved from http://tll.mit.edu/sites/default/files/library/ LINC\%20\%9213.pdf.

Benbunan-Fich, R., \& Hiltz, S. R. (2003). Mediators of the effectiveness of online courses. IEEE Transactions on Professional Communication, 46(4), 298-312.

Bernard, R. M., Abrami, P. C., Lou, Y., Borokhovski, E., Wade, A., Wozney, L., et al. (2004). How does distance education compare with classroom instruction? A meta-analysis of the empirical literature. Review of Educational Research, 74, 379-439.

Breen, J. (2014). http://www.inside-r.org/howto/mining-twitter-airline-consumer-sentiment.

Breslow, L., Pritchard, D. E., DeBoer, J., Stump, G. S., Ho, A. D., \& Seaton, D. T. (2013). Studying learning in the worldwide classroom: Research into edX's first MOOC. Research and Practice in Assessment, 8, 13-25.

Canelas, D. A. (2015). Teaching college chemistry to the edges rather than to the average: Implications for less experienced science students. American Chemical Society Symposium Series 1193. In K. Daus, \& R. Rigsbee (Eds.), The promise of chemical education: Addressing our students' needs (pp. 11-28). Oxford, UK: Oxford University Press.

Chen, Y. (2014). Investigating MOOCs through blog mining. International Review of Research in Open and Distributed Learning, 15(2), 85-106. 
Childs, S., Blenkinsopp, E., Hall, A., \& Walton, G. (2005). Effective e-learning for health professionals and students-barriers and their solutions. A systematic review of the literature-findings from the HeXL project. Health Information \& Libraries Journal, 22, 20-32. http://dx.doi.org/10.1111/j.1470-3327.2005. 00614.x.

Cohen, J., McCabe, E. M., Michelli, N. M., \& Pickeral, T. (2009). School Climate: Research, policy, practice, and teacher education. Teachers College Record, $111(1), 180-213$.

Comer, D. K., Clark, C. R., \& Canelas, D. A. (2014). Writing to learn and learning to write across the disciplines: Peer-to-peer writing in introductory level MOOCs. International Review of Research in Open and Distributed Learning, 15(5), 26-80.

Cooper, S., \& Sahami, M. (2013). Reflections on Stanford's MOOCs. Communications of the ACM, 56(2), 28-30.

DeBoer, J., Stump, G. S., Seaton, D., Breslow, L. (2013). Diversity in MOOC students' backgrounds and behaviors in relationship to performance in 6.002 x. In Proceedings of the Sixth Learning International Networks.

DeBoer, J., Ho, A. D., Stump, G. S., \& Breslow, L. (2014). Changing "course": Reconceptualizing educational variables for massive open online courses. Educational Researcher, 43(2), 74-84.

Dillahunt, T., Wang, Z., \& Teasley, S. D. (2014). Democratizing higher Education: Exploring MooC use among those who cannot afford a formal education. International Review of Research in Open and Distributed Learning, 15(5), 177-195.

Diver, P., \& Martinez, I. (2015). MOOCs as a massive research laboratory: Opportunities and challenges. Distance Education, 36(1), 5-25. http://doi.org/10. $1080 / 01587919.2015 .1019968$

Ebben, M., \& Murphy, J. S. (2014). Unpacking MOOC scholarly discourse: A review of nascent MOOC scholarship. Learning, Media, and Technology, 39(3), $328-345$.

Emanuel, E. J. (2013). Online education: MOOCs taken by educated few. Nature, 503(7476), 342.

Engle, D., Mankoff, C., \& Carbrey, J. (2015). Coursera's introductory human physiology course: Factors that characterize successful completion of a MOOC. International Review of Research in Open and Distributed Learning, 16(2), 46-68.

Ferguson, R., \& Clow, D. (16-20 March 2015). Examining engagement: Analysing learner subpopulations in massive open online courses (MOOCs). In 5th international learning analytics and knowledge conference (LAK15). Poughkeepsie, NY, USA: ACM.

Fidalgo-Blanco, Á., Sein-Echaluce Lacleta, M. L., \& García-Peñalvo, F. J. (2015). Methodological approach and technological framework to break the current limitations of MOOC model. Journal of Universal Computer Science, 21(5), 712-734.

Fidalgo-Blanco, Á., Sein-Echaluce, M. L., \& García-Peñalvo, F. J. (2016). From massive access to cooperation: Lessons learned and proven results of a hybrid xMOOC/cMOOC pedagogical approach to MOOCs. International Journal of Educational Technology in Higher Education, 13, 24.

Gikandi, J. W., Morrow, D., \& Davis, N. E. (2011). Online formative assessment in higher education. Computers and Education, 57(4), $2333-2351$.

Goldberg, L. R., Bell, E., King, C., O'Mara, C., McInerney, F., Robinson, A., et al. (2015). Relationship between participants' level of education and engagement in their completion of the Understanding Dementia massive open online course. BMC Medical Education, 15. Article number 60.

Gooding, I., Klaas, B., Yager, J. D., \& Kanchanaraksa, S. (2013). Massive open online courses in public health. Frontiers in Public Health, 1, 59.

Graham, S., \& Weiner, B. (1996). Theories and principles of motivation. Handbook of Educational Psychology, 4, 63-84.

Greene, J. A., Oswald, C. A., \& Pomerantz, J. (2015). Predictors of retention and achievement in a massive open online course. American Educational Research Journal, 52(5), 925-955.

Halasek, K., McCorkle, B., Selfe, C. L., DeWitt, S. L., Delagrange, S., Michaels, J., et al. (2014). A MOOC with a view: How MOOCs encourage us to reexamine pedagogical doxa. In S. D. Krause, \& C. Lowe (Eds.), Invasion of the Moocs: The Promises and Perils of Massive Open Online Courses. Anderson, South Carolina: Parlor Press.

Hall, D. M., Curtin-Soydan, A. J., \& Canelas, D. A. (2014). The science advancement through group engagement program: Leveling the playing field and increasing retention in science. Journal of Chemical Education, 91(1), 37-47.

Hansen, J. D., \& Reich, J. (2015). Democratizing education? Examining access and usage patterns in massive open online courses. Science, 350(6265), $1245-1248$.

Harder, B. (2013). Are MOOCs the future of medical education? British Medical Journal, 346. Article number f2666.

Hart, C. (2012). Factors associated with student persistence in an online program of study: A review of the literature. Journal of Interactive Online Learning, 11(1), 19-42.

Hartnett, M., St. George, A., \& Dron, J. (2011). Examining motivation in online distance learning environments: Complex, multifaceted, and situationdependent. International Review of Res. in Open and Distributed Learning, 12(6), 20-38.

Hew, K. F., \& Cheung, W. S. (2014). Students' and instructors' use of massive open online courses (MOOCs): Motivations and challenges. Educational Research Review, 12, 45-58.

Hollands, F. M., \& Tirthali, D. (2014). Resource requirements and costs of developing and delivering MOOCs. Int. Rev. Res. Open Dist. Learn., 15(5), 113-133.

Hood, N., Littlejohn, A., \& Milligan, C. (2015). Context counts: How learners' contexts influence learning in a MO0C. Computers and Education, 91, 83-91.

Hoskins, S. L., \& van Hooff, J. C. (2005). Motivation and ability: Which students use online learning and what influence does it have on their achievement? British Journal of Educational Technology, 36(2), 177-192.

Hoxby, C. M. (2014). The economics of online postsecondary education: MOOCs, nonselective education, and highly selective education. American Economic Review, 104(5), 528-533.

Hu, Minqing, Bing, Liu. (2004). Mining and summarizing customer reviews. In Proceedings of the tenth ACM SIGKDD international conference on Knowledge discovery and data mining (pp. 168-177), 22 Aug. 2004.

Keller, J. M. (1979). Motivation and instructional design: A theoretical perspective. Journal of Instructional Development, 2(4), $26-34$.

Kizilcec, R. F., \& Schneider, E. (2015). Motivation as a lens to understand online Learners: Toward data-driven design with the OLEI scale. ACM Transactions on Computer Human Interaction, 22(2). article no. 6.

Kolowich, S. (2013). Why professors at San Jose State University won't use a Harvard professor's MOOC. The Chronicle of Higher Education. http://chronicle. com/article/Why-Professors-at-San-Jose/138941/ (Accessed 18 May 2015).

Krueger, Richard A. (2006). Analyzing focus group interviews. Journal of wound, ostomy, and continence nursing, 33(5), $478-481$.

Leacock, T. L., \& Nesbit, J. C. (2007). A framework for evaluating the quality of multimedia learning resources. Educational Technology and Society, 10(2), 44-59.

Lee, Y., \& Choi, J. (2011). A review of online course dropout research, implications for practice and future research. Educational Technology Research and Development, 59(5), 593-618.

Lei, S. A. (2010). Intrinsic and extrinsic motivation: Evaluating benefits and drawbacks from college instructors' perspectives. Journal of Instructional Psychology, 37(2), 153-160.

Leontyev, A., \& Baranov, D. (2013). Massive open online courses in chemistry: A comparative overview of platforms and features. Journal of Chemical Education, 90, 1533-1539.

Liyanagunawardena, T. R., Adams, A. A., \& Williams, S. A. (2013). MOOCs: A systematic study of the published literature 2008-2012. The International Review of Research in Open and Distributed Learning, 14(3), 202-227.

Liyanagunawardena, T. R., \& Williams, S. A. (2014). Massive open online courses on health and medicine: Review. Journal of Medical Internet Research, 16(8), e191.

Ma, J. D., Lee, K. C., \& Kuo, G. M. (2013). A massive open online course on pharmacogenomics: Not just disruptive innovation but a possible solution. Pharmacogenomics, 14(10), 1125-1127.

Marshall, S. (2014). Exploring the ethical implications of MOOCs. Distance Education, 35(2), $250-262$.

Martin, F. G. (2012). Will massive open online courses change how we teach? Communications of the ACM, 55(8), 26-28.

Maxwell, J. A. (2005). Qualitative research design: An interactive approach (2nd ed.). Thousand Oaks, CA: Sage. 
McNutt, M. (2013). Bricks and MOOCs. Science, 342, 402.

Moore, J. S., \& Janowicz, P. A. (2009). Chemistry goes global in the virtual world. Nature Chemistry, 1, 2-4.

Murphy, K., \& Monk, P. L. (2013). Continuing medical education: MOOCs (massive open online courses) and their implications for radiology learning. Canadian Association of Radiologists Journal, 64(3), 165.

Park, J.-H., \& Choi, H. J. (2009). Factors influencing adult leaners' decision to drop out or persist in online learning. Educational Technology and Society, 12(4), 207-217.

Parkes, M., Stein, S., \& Reading, C. (2015). Student preparedness for university e-learning environments. Internet and Higher Education, 25, 1-10.

Phan, T., McNeil, S. G., \& Robin, B. R. (2016). Students' patterns of engagement and course performance in a massive open online course. Computers and Education, 95, 36-44.

Rhoads, R. A., Camacho, M. S., Toven-Lindsey, B., \& Lozano, J. B. (2015). The massive open online course movement, xMOOCs, and faculty labor. Review of Higher Education, 38(3), 397-424.

Roca, J. C., Chiu, C.-M., \& Martínez, F. J. (2006). Understanding e-learning continuance intention: An extension of the Technology Acceptance Model. International Journal of Human-Computer Studies, 64(8), 683-696.

Sandelowski, M., \& Barroso, J. (2003). Classifying the findings in qualitative studies. Qualitative Health Research, 13(7), 905-923.

Song, L., \& Hill, J. R. (2007). A conceptual model for understanding self-directed learning in online environments. Journal of Interactive Online Learning, 6(1), $27-42$.

Sun, P.-C., Tsai, R. J., Finger, G., Chen, Y.-Y., \& Yeh, D. (2008). What drives a successful e-learning? An empirical investigation of the critical factors influencing learner satisfaction. Computers and Education, 50, 1183-1202.

Toven-Lindsey, B., Rhoads, R. A., \& Lozano, J. B. (2015). Virtually unlimited classrooms: Pedagogical practices in massive open online courses. Internet and Higher Education, 24, 1-12.

U.S. Department of Education. (2010). Office of planning, evaluation, and policy development, evaluation of evidence-based practices in online learning: A metaanalysis and review of online learning studies. Washington, D.C. https://www2.ed.gov/rschstat/eval/tech/evidence-based-practices/finalreport.pdf (Accessed 28 August 2015)

Vivian, R., Falkner, K., \& Falkner, N. (2014). Addressing the challenges of a new digital technologies curriculum: MOOCs as a scalable solution for teacher professional development. Research in Learning Technology, 22, 24691.

Waldrop, M. M. (2013). Online learning: Campus 2.0. Nature, 495(7440), 160-163.

Wiebe, E., Thompson, I., \& Behrend, T. (2015). MOOCs from the viewpoint of the learner: A response to Perna et al. (2014). Educational Researcher, 44(4), $252-254$.

Yang, Q. (2014). Students motivation in asynchronous online discussions with MOOC mode. American Journal of Educational Research, 2(5), 325-330.

Zawacki-Richter, O., Bäcker, E. M., \& Vogt, S. (2009). Review of distance education research (2000 to 2008): Analysis of research areas, methods, and authorship patterns. International Review of Research in Open and Distributed Learning, 10(6), 21-50. 